\title{
A Novel Hysteresis Current Controller Based on ITAE Optimal Control
}

\author{
Li Jun ${ }^{1}$ Wang Dazhi ${ }^{1}$ \\ Institute of Electric Power System and Motor Drives \\ College of Information Science and engineering Northeastern University \\ Shenyang, Liaoning P.R. China \\ E-mail: li-versatile@163.com
}

\begin{abstract}
Current control strategy is the key to an active power filter's compensation effects. An novel optimal hysteresis current controller with variable-band is presented. This paper discusses the principle of hysteresis current control, the way to realize variable-band optimal control, and gives a optimal control law generated from simulation. Simulation effects show that dynamic behavior of the controller is better than controller with no optimal control .The simulation results of also verify that the controller is superior to controller with fixed-band hysteresis .
\end{abstract}

Keywords-- active power filter; variable-band ; hysteresis current control ; optimal control

\section{INTRODUCTION}

Active power filter (APF) is widely used to mitigate power system harmonics and compensate reactive power. Current control strategy selection is the key to an APF. Now power electronic switches are usually controlled by the PWM switching signal which is generated by microprocessor or digital signal processor (DSP) according to different algorithms ${ }^{[1,2]}$.Hysteresis current control method is widely applied in the APF for its high precision, good stability and fast response. Unfortunately, Hysteresis with fixed-band would cause unsatisfactory compensation effects at zero-crossing point and a wide range of switching frequency. Paper [3] has described the connection between time delay and stability, but not Optimized PWM converters to the APF.A novel hybrid control scheme based on the variable-band digital hysteresis control and repetitive control is proposed in Paper [4], but it has not pointed out the foundation of variable-band. In fact, transfer function of PWM converters has a time-delay link which can not be simply regarded as first-order or second order system at high frequency occasions. To obtain good dynamic behavior, optimal control for PWM converters is necessary. Optimal control based on Integral Time Absolute Error (ITAE) combined with variable-band hysteresis current control method is proposed according to problems of hysteresis current control ${ }^{[3 \sim 9]}$.The simulation results of
MATLAB and PSIM show that the method has good dynamic behavior and compensation effects.

II VARIABLE-BAND HYSTERESIS CURRENT CONTROL

Fig.1 shows the chart of variable-band hysteresis current control. In Fig. 1 , command current $i^{*}$ derives from digital controller according to instantaneous reactive power theory, and current $i$ is detected by current sensor; expected switching frequency $f^{*}$ is given by the designer and switching frequency $f$ is detected by the switching frequency detector. Then the command current $i^{*}$, expected switching frequency $f^{*}$ subtracts the actual current $i$, actual switching frequency respectively. The frequency difference is sent to PI controller. Circuit of hysteresis comparator with variable-band shown in Fig.2 gives the way of changing hysteresis band. Comparator is used to generate PWM control signal. Then the optimized signal is used to control switches to generate compensatory harmonics $i_{a}$.

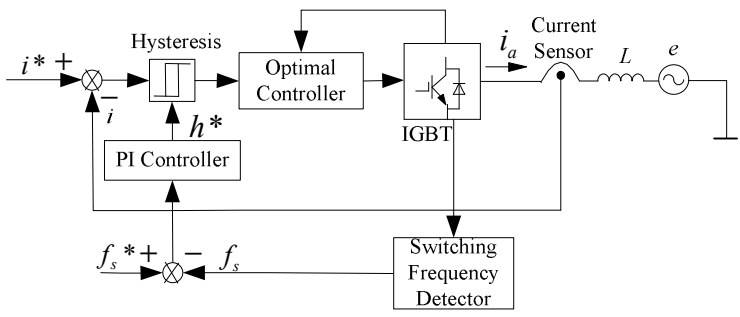

Fig.1 Chart of variable-band hysteresis current control

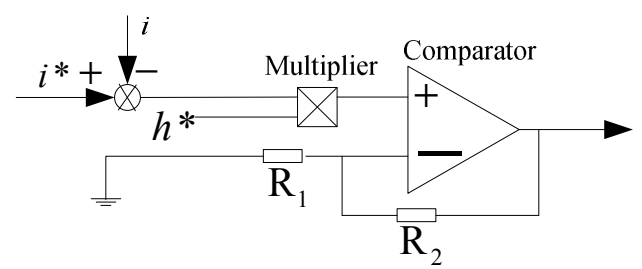

Fig.2 Circuit of variable-band hysteresis comparator 


\section{ITAE OPTIMAL CONTROL}

PWM converters are difficult to be optimized for their time-delay link. Added by processing time, transfer function of converters can be expressed as:

$$
f(s)=\frac{U_{o}(s)}{U_{c}(s)}=K_{s} e^{-\tau s}
$$

Where, $U_{0}(s), U_{c}(s), \tau, e^{-\tau s}, K_{s}$ are average voltage of PWM converters without load, pulse-duration modulation control voltage, total delay time of control signal and dead-time of switches, infinite dimension factor and voltage amplification factor respectively. State observer of system shown in Fig.3 is built according to dimension of transfer function and the number of independent controllable variables. The second-time optimal block is shown in the empty box.

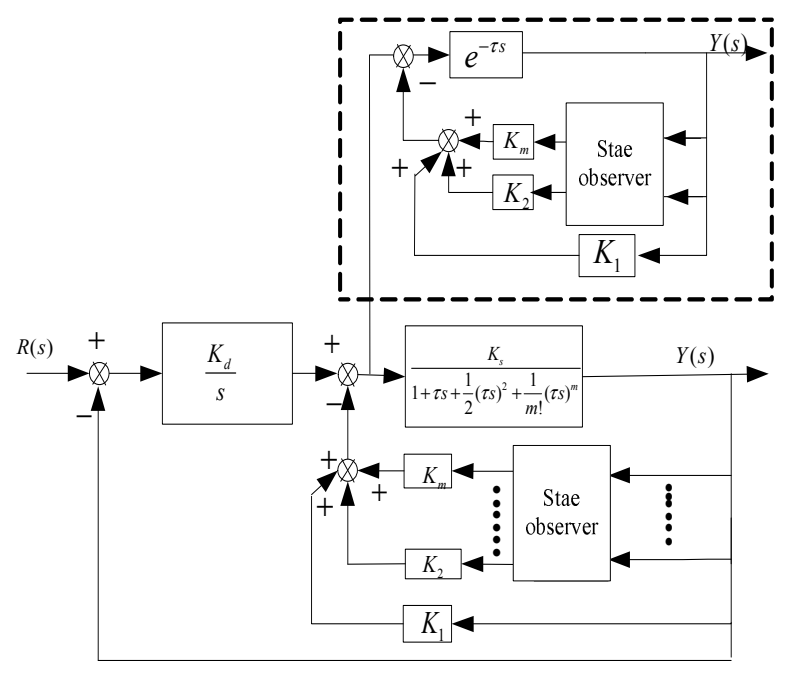

Fig.3 State observer of system

M-dimension feedback general formula and open-loop transfer function of the system are described as formula (4), (5).

$$
\begin{gathered}
F_{m}(s)=\sum_{i=0}^{m} k_{i} s^{i-1} \\
W_{o m}=\frac{K_{d} f(s)}{s\left[1+f(s) F_{m}(s)\right]}
\end{gathered}
$$

Where, $i=m \in \mathrm{N}, K_{d}, K_{i}$ are integral coefficient state-feedback coefficient respectively.

If open-loop transfer function of system meets formula (6), the system would have no static displacement error. With the help of computer, optimal control law can be got if the simulation model meets index formula (7):

$$
W(s)=\frac{1}{s\left(s^{n}+\alpha_{n-1} s^{n-2}+\ldots+\alpha_{1}\right)}
$$

Where, $\alpha_{i}$ stands for coefficient of standard transfer function .

$$
J(\mathrm{ITAE})=\int_{0}^{\tau_{\mathrm{s}}} t|e(t)| d t=\min
$$

Where, $\tau_{s}$ is time of transition process and $e(t)$ is error of system.

The general formula of state-feedback coefficient by comparing all orders is shown as:

$$
\left.\begin{array}{l}
k_{d}=\frac{1}{K_{s}} \tau^{m} \omega_{0 m}{ }^{m+1} \\
k_{i}=\frac{1}{K_{s}}\left(\frac{1}{m !} \alpha_{i} \tau^{m} \omega_{0 m}{ }^{m}-\frac{1}{(m-1) !} \tau^{m-1}\right)
\end{array}\right\}
$$

Where, $\omega_{0 m}$ stands for optimal scale.

Performance index $J_{\min }, \sigma \%, \tau_{s}$ and optimal parameters $\alpha_{i}$ are shown in Tab.1 when $W(s)$ is second-order, third-order, forth-order and $e\left(\tau_{s}\right)$ is less than or equal to one percent.

Tab.1 ITAE transfer function and optimal performance index

$$
\text { When } e\left(\tau_{s}\right) \text { is less than or equal to one percent. }
$$

\begin{tabular}{c|c|c|c|c|c|c}
\hline$\alpha_{i}$ & $\alpha_{3}$ & $\alpha_{2}$ & $\alpha_{1}$ & $\sigma \%$ & $\tau_{s}$ & $J_{\min }$ \\
\hline 4 & 1.54 & 3.08 & 2.39 & 5.00 & 3.72 & 3.42 \\
\hline 3 & & 1.50 & 2.02 & 4.99 & 3.20 & 2.23 \\
\hline 2 & & & 1.38 & 4.98 & 2.84 & 1.36 \\
\hline
\end{tabular}

General formula of infinite-dimension state feedback is expressed as formula (8) when expression of state feedback is replaced by the time-delay factor. 


$$
F_{m e}(s)=\frac{\sum_{i=0}^{m} k_{i} s^{i-2}}{\sum_{i=1}^{m} \frac{(\tau s)^{m}}{m !} s^{i-1}}\left(e^{\tau s}-1\right)+k_{1}
$$

The corresponding open-loop transfer function of infinite-dimension state feedback is described as:

$$
W_{\text {ome }}=\frac{K_{d} f(s)}{s\left[1+f(s) F_{m e}(s)\right]}
$$

Optimal scale is obtained when formula (9) is employed with the help of MATLAB. Set of every order optimal parameters shown in Tab.2 can be got when they meet performance index $\sigma \% t_{s}=\min$ and other kinds of index are took into account.

\begin{tabular}{|c|c|c|c|c|c|c|c|c|}
\hline \multicolumn{2}{|c|}{ parameters $\tau$} & 0.1 & 0.2 & 0.5 & 1.0 & 2.0 & 4.0 & average \\
\hline \multirow{4}{*}{$m=1$} & $\omega_{01}$ & 8.2356 & 4.2652 & 1.7224 & 0.8449 & 0.4229 & 0.2066 & \\
\hline & $\sigma \%$ & 0 & 0 & 0 & 0 & 0 & 0 & 0 \\
\hline & $\tau_{s}$ & 3.265 & 3.073 & 3.188 & 3.063 & 3.045 & 3.080 & 3.119 \\
\hline & $\tau \omega_{01}$ & 0.8236 & 0.8530 & 0.8612 & 0.8449 & 0.8458 & 0.8264 & 0.8425 \\
\hline \multirow{4}{*}{$m=2$} & $\omega_{02}$ & 11.3212 & 5.9775 & 2.5436 & 1.2199 & 0.5996 & 0.3021 & \\
\hline & $\sigma \%$ & 1.01 & 1.00 & 1.00 & 1.03 & 1.00 & 1.02 & 1.01 \\
\hline & $\tau_{s}$ & 2.583 & 2.503 & 2.232 & 2.369 & 2.485 & 2.445 & 2.436 \\
\hline & $\tau \omega_{02}$ & 1.1321 & 1.1955 & 1.2718 & 1.2199 & 1.1992 & 1.2084 & 1.2045 \\
\hline \multirow{4}{*}{$m=3$} & $\omega_{03}$ & 15.1911 & 7.5739 & 2.9110 & 1.4609 & 0.7528 & 0.3781 & \\
\hline & $\sigma \%$ & 1.52 & 1.53 & 1.50 & 1.52 & 1.51 & 1.50 & 1.51 \\
\hline & $\tau_{s}$ & 2.419 & 2.447 & 2.618 & 2.603 & 2.469 & 2.463 & 2.503 \\
\hline & $\tau \omega_{03}$ & 1.5191 & 1.5148 & 1.4555 & 1.4609 & 1.5056 & 1.5124 & 1.4947 \\
\hline
\end{tabular}

Tab.2 Set of parameters to second time optimal system

Empirical formula of optimal control law got from Tab. 2 is expressed as:

$$
\left.\begin{array}{rl}
\tau \omega_{0 m} & =\text { const } \\
\sigma_{m}^{0} \% & =\text { const } \\
\tau_{s m} & =\text { const }
\end{array}\right\}
$$

Where, $\tau_{s m}=\frac{\tau_{s}}{\tau}$ is standard time of transition process. Average of the three parameters in the formula (10) is used as value of empirical parameters.

Then optimal design of system can be simplified by consulting Tab.2 and formula (4).

\section{SIMULATION RESULTS}

Fig.5 shows the result of simulation of MATLAB, checking PWM transfer function of converters for $K_{s}=1.0, \tau=0.00002 \mathrm{~s}$ respectively. In the model, amplitude of signal and cycle are $0.1,0.002 s$ respectively. Fig.4, Fig.6 and Fig.7 are simulation results of PSIM model.

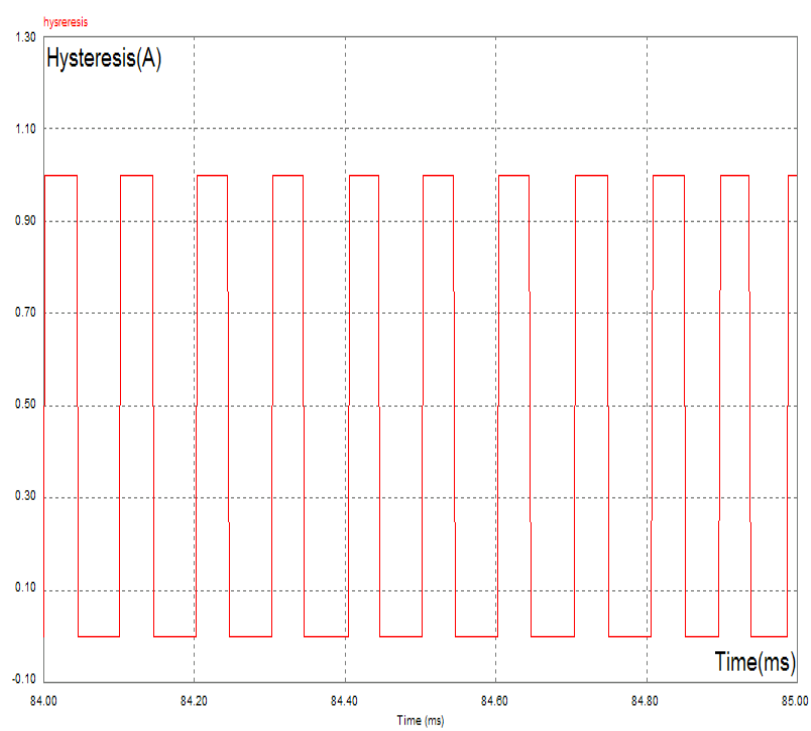

Fig.4 switching frequency of the optimal controller

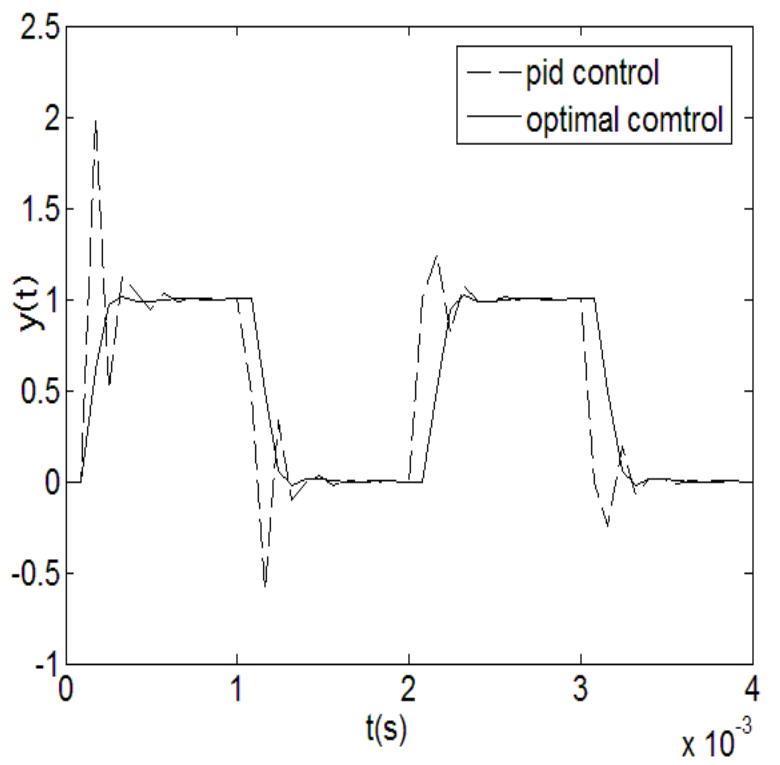

Fig. 5 Simulation of different algorithms 


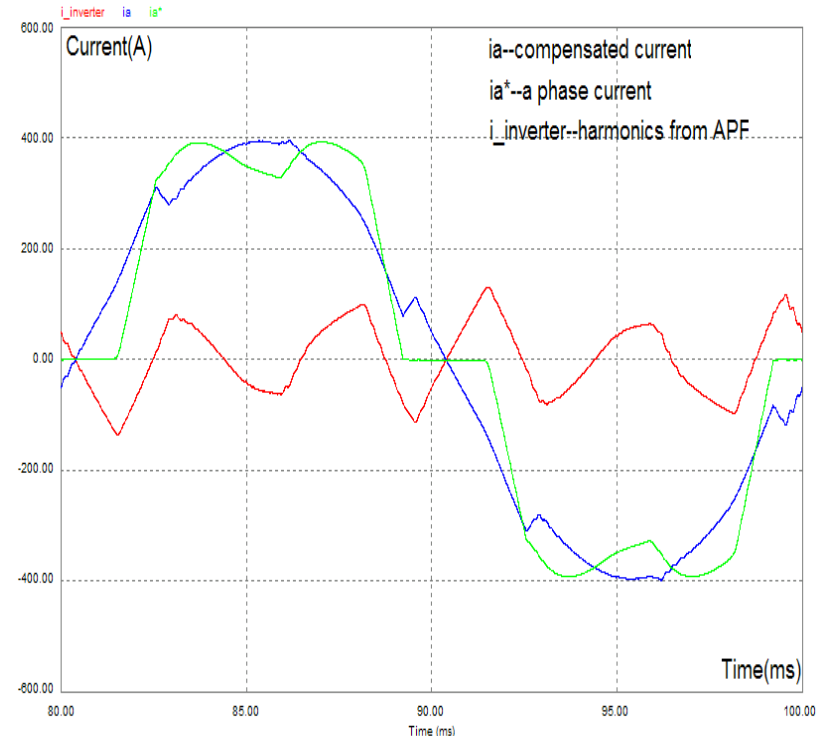

Fig.6 Simulation of APF controlled by the optimal controller

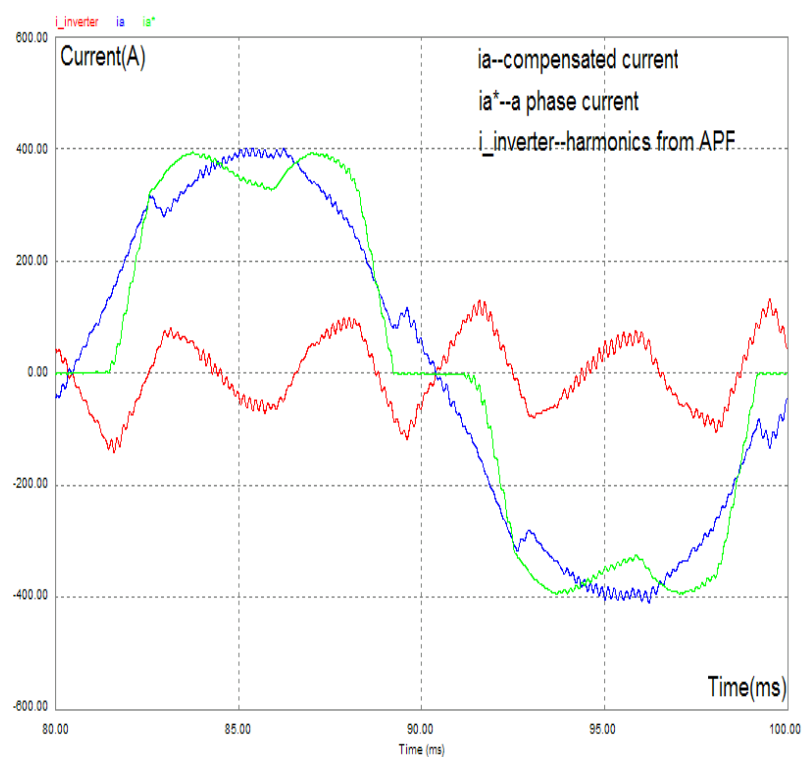

Fig.7 Simulation of APF controlled by PID controller

IV CONCLUSION
The Fig.4 and Fig.5 show that the controller has relatively stable switching frequency, good dynamic performance when it is used to trace signal. Fig. 6 and Fig.7 show that the optimal controller is superior to the PID controller in harmonics suppression.

\section{ACKNOWLEDGMENT}

The authors would like to thank the National 211 Project (28110514).

\section{REFERENCES}

[1] Kwon Y N, Lee Y S, Lee J H. "Research of Harmonic Detection and Fuzzy-pid Control in Series Active Power Filter, " Proceedings of the 2007 IEEE International Conference on Mechatronics and Automation, ICMA 2007, pp. 2957-2962, Aug. 2007.

[2] Muhanmmad H. Rashid. Power Electronics, 3rd ed., vol. 1.Beijing: Post \& Telecom Press, 2007, pp.166-293.

[3] Tang Ci , Luo An, Zhao Wei ,Shuai Zhikang. "Stability of Hybrid Shunt Active Power Filters." Proceedings of the CSEE. China, vol. 28, pp. 43-47,Feb. 2008.

[4] Xu Zhonghua, Ye Lan, He Zhongyi, Xing Yanl. "A Hybrid Control Scheme for DPM Inverters Based on Variable-band Hysteresis Control and Repetitive Control." Inverting Power Supply,pp. 49-51 ,July 2008.

[5] Xiang Guo-bo. Optimal Control of Time-delay System,1st ed., vol.1.Beijing: China Electric Power Press, 2008,pp..1-57.

[6] ZHANG Fu-bo,WANG Guodong,ZHANG Dianhua , Liu Xianghua. "Optimal ITAE Tuning Formulate for Parameters of PID Controller.'Journal of Northeastern University (Natural Science), pp.757-756, August 2005

[7] Marian Kazimierziczuk. "Transfer Function of Current Modulator in PWM Converters with Current-mode Control." IEEE Tans,Vol.47,pp.1407-1402,September 2000

[8] Wang Xiuli, Wang Yongji, Zhou Hui. "Optimal Design AQM Routers with D-Stable Regions Based on ITAE Performance ." HUT-ICCE 2006 First International Conference on Communications and Electronics ,pp.229-232.July 2007.

[9] Luo Shiguo. "Optimal Design of Dc Voltage Close Loop Control for An Active Power Filter." Proceedings of the International Conference on Electrical Engineering ICEE '96,pp.79-81,Feb. 1995. 